\title{
Robotic-Assisted Neck Dissection: Our Experience
}

\author{
Salvatore Poma ${ }^{1, *(1)}$ Domenico Michele Modica ${ }^{1,2, *(1)}$ Alessandro Pitruzzella ${ }^{2(-)}$ Alberto Fucarino ${ }^{2(1)}$ \\ Gianfranco Mattina ${ }^{1,2}$ Salvatore Fasola ${ }^{3 \odot}$ Daniele Pirrello ${ }^{4}{ }^{\circledR}$ Giuseppe Mario Galfano ${ }^{1}$
}

1 U.O.C. Otolaryngology, Ospedali Riuniti Villa Sofia-Cervello, Palermo, Italy

2 U.O.C. Department of Biomedicine, Neuroscience and Advanced Diagnostics, Institute of Human Anatomy and Histology, University of Palermo, Palermo, Italy

${ }^{3}$ Institute of Biomedicine and Molecular Immunology, "A. Monroy"

(IBIM), CNR, Palermo, Italy

${ }^{4}$ University of Palermo, Bionec, Palermo, Italy

Int Arch Otorhinolaryngol 2022;26(1):e178-e182.
Address for correspondence Alessandro Pitruzzella, PhD, Department of Biomedicine, Neuroscience and Advanced Diagnostics, Institute of Human Anatomy and Histology, University of Palermo, Palermo, Italy (e-mail: alexpitruzzella@libero.it).

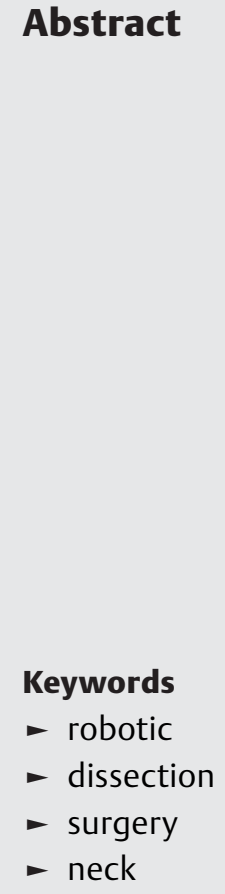

Introduction Robotic neck dissection surgery allows less invasiveness to significantly improve the aesthetic impact even though it does not compromise the principles of radical cancer procedure.

Objective The aim of our work is to describe our personal experience with robotic neck dissection surgery.

Methods A retrospective study was conducted by analyzing 10 patients subjected to a robotic neck dissection surgery. In the period from August 2012 to December 2018, these patients have been treated exclusively with robotic lateral-cervical dissection. Five of them were subjected to robotic-assisted transaxillary neck dissection (RATAND) and the other 5 treated with robotic-assisted retroauricular neck dissection (RARAND), then the surgical results have been compared with 5 similar dissections performed by open neck dissection (OND).

Results The average surgical time of RATAND was estimated in 166 minutes, the average surgical time of RARAND was estimated in 153 minutes and the average surgical time of OND was estimated in 48 minutes. Both robotic techniques are valid from the oncological and aesthetic point of view, but in terms of surgical time, they are much longer than the open technique.

Conclusions In terms of the post-operative decree, in our opinion, the retroauricular technique is more rapid for the purposes of recovery.

\section{Introduction}

Selective neck dissection is a widespread procedure in otorhinolaryngology, targeting the oncological radicalization of tumor metastases. The transition from radical dissec-

\footnotetext{
* These authors contributed equally to this work.
}

received

October 3, 2019

accepted

August 23, 2020

published online

March 29, 2021
DOI https://doi.org/ $10.1055 / \mathrm{s}-0040-1718957$ ISSN 1809-9777. tion to more modern selective dissection has gone through several stages since the latter was introduced in the second half of the $19^{\text {th }}$ century. Surgical field developments had been supported by evolution of anatomical knowledge along with technological progress with the aim of less invasiveness. These new techniques significantly improve the aesthetic impact and, at the same time, they do not undermine
(C) 2021. Fundação Otorrinolaringologia. All rights reserved.

This is an open access article published by Thieme under the terms of the Creative Commons Attribution-NonDerivative-NonCommercial-License, permitting copying and reproduction so long as the original work is given appropriate credit. Contents may not be used for commercial purposes, or adapted, remixed, transformed or built upon. (https://creativecommons.org/ licenses/by-nc-nd/4.0/)

Thieme Revinter Publicações Ltda., Rua do Matoso 170, Rio de Janeiro, RJ, CEP 20270-135, Brazil 
the principles of radical cancer treatment. In fact, the robotic neck dissection surgery (described by Kang et al. ${ }^{1,2}$ in 2010 with a transaxillary approach and by Lee et al. ${ }^{12}$ in 2012 with a retroauricular approach) lays the foundations for a concomitant surgical radicalism and minor impact on the anatomical structures treated. In the past 10 years, the "Da Vinci" surgical robot (Intuitive Surgical, Inc. 1020 Kifer RoadSunnyvale, CA) has greatly improved the approaches to anatomical sites that are difficult to explore without a correct and wide exposure. Its use has provided to the surgeon alternative approaches with less invasiveness for those districts previously treated with the classic open technique. The transoral surgery (TORS) has benefited from the possibility of reaching the surgical site and to enjoy a close-up vision, making several structures more approachable (laryngeal district, parapharyngeal spaces, thyroid gland, etc.). In addition, with the most modern retroauricular approaches (facelift-incision) appears even easily reachable, with a reduction on the aesthetic impact.

The aim of our work is to describe our experience of robotic surgery that includes all cervical-facial surgery, including the most modern approaches to the neck that are still not widespread in Europe, with the purpose of increasing knowledge and case history relating to the different latero-cervical emptying techniques, comparing these approaches with the "traditional" open technique.

\section{Materials and Methods}

A retrospective study was conducted at our Otolaryngology Unit in Palermo by analyzing among the 56 procedures performed by surgical robot in the period from August 2012 to December 2018. A total of 10 patients, respectively 8 males and 2 females, with an average age of 64 years old, have been subjected exclusively to robotic lateral-cervical dissection: 5 surgery procedures were performed with robotic assisted transaxillary neck dissection (RATAND) and the other 5 with robotic assisted retroauricular neck dissection (RARAND). At the same time, we compared the results obtained with other 5 dissections performed by standard open neck dissection (OND) on, respectively, 3 males and 2 females, with an average age of 60 years old. The demographics and oncological history of the included patients are given in -Table $\mathbf{1}$.

We included in the analysis patients subjected to unilateral lateral-cervical dissection of levels II-IV with the surgery time necessary to perform the procedure measured from the skin incision to the skin closure, then we compared the time with similar procedures performed with the other different approaches. We classified the patients according to the Tumor - Node - Metastasis (TNM) classification of Malignant Tumors and we excluded from the study those patients previously operated by neck dissection, to avoid an "altered" operating field. And we have also documented about previous chemotherapies performed on the treated subjects. These data are summarized in - Table 1. In addition to the average duration of surgery treatment, we analyzed the average time taken to remove the surgical drainage, the average length of hospitalization and possible onset of
Table 1 Baseline characteristics of included patients

\begin{tabular}{|c|c|c|c|c|}
\hline & $\begin{array}{l}\text { RATAND } \\
(n=5)\end{array}$ & $\begin{array}{l}\text { RARAND } \\
(n=5)\end{array}$ & $\begin{array}{l}\text { OND } \\
(n=5)\end{array}$ & p-value \\
\hline $\begin{array}{l}\text { Gender } \\
\text { (Male:Female) }\end{array}$ & $4: 1$ & $4: 1$ & $2: 3$ & 0.500 \\
\hline $\begin{array}{l}\text { Medium } \\
\text { age, range }\end{array}$ & $\begin{array}{l}55.2 \\
(48-67)\end{array}$ & $\begin{array}{l}53.6 \\
(45-62)\end{array}$ & $\begin{array}{l}60.8 \\
(44-80)\end{array}$ & 0.577 \\
\hline BMI & $\begin{array}{l}27 \\
(23-30)\end{array}$ & $\begin{array}{l}27 \\
(22-30)\end{array}$ & $\begin{array}{l}27.4 \\
(25-32)\end{array}$ & 0.971 \\
\hline \multicolumn{5}{|l|}{ Primary site } \\
\hline Tonsil & 2 & 1 & 0 & \\
\hline BOT & 1 & 1 & 0 & \\
\hline Hard palate & 0 & 1 & 0 & \\
\hline Larynx & 2 & 2 & 3 & \\
\hline Occult & 0 & 0 & 2 & \\
\hline \multicolumn{5}{|l|}{ T Stage } \\
\hline 1 & 1 & 2 & 0 & \\
\hline II & 4 & 3 & 0 & \\
\hline III & 0 & 0 & 3 & \\
\hline IV & 0 & 0 & 2 & \\
\hline$x$ & 0 & 0 & 0 & \\
\hline \multicolumn{5}{|l|}{ N Stage } \\
\hline \multicolumn{5}{|l|}{0} \\
\hline I & 1 & 3 & 0 & \\
\hline Ila & 2 & 1 & 1 & \\
\hline Ilb & 2 & 1 & 2 & \\
\hline IIC & 0 & 0 & 2 & \\
\hline III & 0 & 0 & 0 & \\
\hline \multicolumn{5}{|l|}{ Previous CRT } \\
\hline Yes & 2 & 1 & 2 & \\
\hline No & 3 & 4 & 3 & \\
\hline
\end{tabular}

Abbreviations: BOT, base of tongue; OND, open neck dissection; Previous CRT, previous chemo-radio-therapy; RARAND, robotic assisted retroauricular neck dissection; RATAND, robotic assisted transaxillary neck dissection; TNM, T (Primary tumor) N (Lymph nodes), M (Metastasis).

*ANOVA test for quantitative variables, Fisher's Exact test for categorical variables

mid- and long Turkey's complications. All patients were then reassessed by follow-up.

For the statistical analysis, we used the analysis of variance (ANOVA) test for quantitative variables for comparing the three groups; the Fisher exact test for categorical variables and the Tukey's honest significance test for pairwise comparisons.

\section{Surgical Techniques}

\section{Robotic Assisted Retroauricular Neck Dissection (RARAND)}

In the retroauricular approach, the patient is placed on the operating table in the supine position by using rolls under the shoulders. We proceed to the correct hyperextension of 


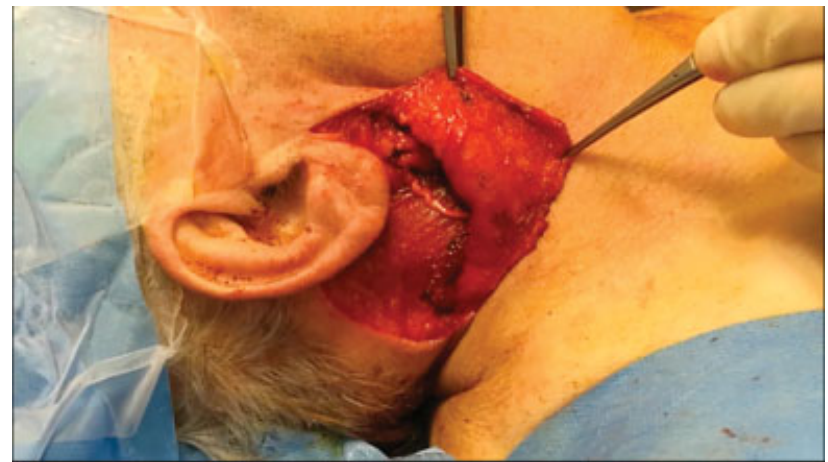

Fig. 1 Retroauricular incision for facelift approach

the neck. An incision is made anteriorly to the tragus and transported inferiorly under the lobule and continued in a retroauricular manner up to the hairline [-Fig. 1]. The subplatysma flaps are raised anteriorly to the level of the sternocleidomastoid muscle. The fascia above the sternocleidomastoid muscle is then incised and sectioned, taking care to maintain the integrity of the great auricular nerve. A modified Modena retractor is introduced to expose the operating field, and the da Vinci surgical robot is introduced and anchored in the operating field. Two robotic arms and the $0^{\circ}$ endoscope are positioned through the facelift incision. A $5 \mathrm{~mm}$ Maryland dissector and a $5 \mathrm{~mm}$ harmonic scalpel are used for robotic dissection. We proceed to find the digastric muscle and to look for the accessory nerve. The posterior face of the digastric muscle is pulled above by retraction. The hypoglossal nerve is identified and protected, the dissection of the tissue begins with attention to visualizing and preserving the accessory nerve. The dissection is performed up to the level of the clavicle to release the tissue, with care to ensure hemostasis. The lymphoadipose package is then dissected away from the jugular vein and the carotid artery with the assistance of the surgical robot [-Fig. 2]. Careful hemostasis is obtained at the end of the case and the robot is removed from the surgical field. After irrigation of the surgical site, a Jackson Pratt (JP) suction discharge is placed, and the skin is closed in several layers in the standard way.

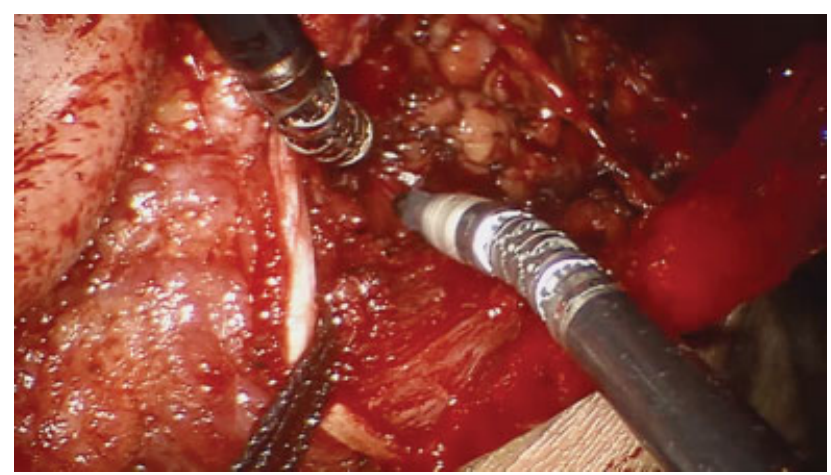

Fig. 2 Complete lymph node emptying

\section{Robotic Assisted Transaxillary Neck Dissection (RATAND)}

In robotic surgery with a transaxillary approach, a vertical skin incision of between 7 and $8 \mathrm{~cm}$ in the axilla along the anterior axillary fold and the lateral margin of the pectoralis major muscle is performed. We then proceed to the detachment with adequate hemostasis of the planes above the pectoralis major muscle until reaching the sternocleidomastoid muscle and then the modified Modena retractor is positioned. From this point on, the procedural steps were analogous to those of the RARAND technique until the end of the surgical procedure.

\section{Open Neck Dissection (OND)}

The dissection has been performed following the established timing of selective neck dissection. Laterocervical incision along the anterior edge of the sternocleidomastoid muscle and incision of the platysmatic plane were performed. The subplatysma flaps were raised anteriorly to the level of the sternocleidomastoid muscle. Afterwards, the fascia above the sternocleidomastoid muscle was incised and sectioned, taking care to maintain the integrity of the large auricular nerve. As in the two robotic assisted techniques, the subsequent steps are identical to what was seen previously.

\section{Results}

The average surgery time of patients who underwent neck dissection performed trough the robotic transaxillary approach was estimated in 166 minutes; the drainage was removed usually after the $6^{\text {th }}$ day with an average collection of blood drained of $108 \mathrm{ml}$ and with a hospitalization time of 6.4 days in average. No postoperative complications were reported, neither at the medium or long term.

Performing the neck dissection trough robotic retroauricular approach gave as outputs: an average surgery time of 153 minutes, the removal of the drainage occurred usually after the $4^{\text {th }}$ day with an average collection of $62 \mathrm{ml}$ and with a hospitalization time of 4 days for the patients. In the same way, no postoperative complications were reported.

The average surgery time of patients who underwent a lateral-cervical emptying on an open approach was estimated in 48 minutes, the drainage was removed usually after the $4^{\text {th }}$ day with an average collection of $82 \mathrm{ml}$ and a hospitalization time of 5 days. In the same way, no postoperative complications were reported.

The functional and immediate post- and perioperative results with pairwise comparison are shown in - Table 2 .

\section{Discussion}

Lateralcervical robotic surgical approaches have been introduced with the aim to reduce the aesthetic impact of postoperative scars. As Kang et al. described in 2010, ${ }^{1,2}$ the transaxillary approach allows to reduce even more the aesthetic impact, granting an access to the cervical region in a lateral-lateral way. In fact, the study by Kang reported a series of 165 patients with papillary thyroid carcinoma who 
Table 2 Results of the study

\begin{tabular}{|c|c|c|c|c|c|c|c|}
\hline & RATAND & RARAND & OND & P-VALUE & $\begin{array}{l}\text { RATAND vs } \\
\text { RARAND } \\
\text { P-VALUE }\end{array}$ & $\begin{array}{l}\text { RATAND } \\
\text { vs OND } \\
P \text {-VALUE }\end{array}$ & $\begin{array}{l}\text { RARAND } \\
\text { vs OND } \\
\text { P-VALUE }\end{array}$ \\
\hline $\begin{array}{l}\text { AVERAGE } \\
\text { OPERATING TIME }\end{array}$ & $166(120-220)$ & $152(90-230)$ & $48(35-60)$ & 0.002 & 0.864 & 0.002 & 0.006 \\
\hline $\begin{array}{l}\text { INTRAOPERATIVE } \\
\text { BLOOD LOSS }\end{array}$ & $80(50-100) \mathrm{mL}$ & $\begin{array}{l}55.8(45-70) \\
\mathrm{mL}\end{array}$ & $\begin{array}{l}56(30-100) \\
\mathrm{mL}\end{array}$ & 0.145 & 0.193 & 0.198 & 0.999 \\
\hline $\begin{array}{l}\text { NUMBER OF } \\
\text { LYMPH NODES }\end{array}$ & $29.4(26-33)$ & $28.6(24-36)$ & $26.6(24-30)$ & 0.439 & 0.928 & 0.426 & 0.638 \\
\hline BLOOD DRAINAGE & $108(70-170) \mathrm{mL}$ & $\begin{array}{l}62(40-80) \\
\mathrm{mL}\end{array}$ & $\begin{array}{l}82(60-100) \\
\mathrm{mL}\end{array}$ & 0.056 & 0.046 & 0.311 & 0.487 \\
\hline $\begin{array}{l}\text { HOSPITALIZATION } \\
\text { TIME (DAYS) }\end{array}$ & $6.4(5-10)$ & $4(3-5)$ & $5(4-6)$ & 0.054 & 0.045 & 0.286 & 0.511 \\
\hline $\begin{array}{l}\text { DRAINAGE REMOVAL } \\
\text { IN DAYS }\end{array}$ & $6.2(5-10)$ & $4(3-5)$ & $5(4-6)$ & 0.092 & 0.077 & 0.411 & 0.532 \\
\hline
\end{tabular}

Abbreviations: OND, open neck dissection; RARAND, robotic assisted retroauricular neck dissection; RATAND, robotic assisted transaxillary neck dissection.

*ANOVA test for comparing the three groups

“*Tukey's honest significance test for pair wise comparisons

underwent neck dissection procedure; they have been divided into 2 groups: 56 patients formed the robotic procedure group and the other 109 the conventional open procedure group. At the end of the study, Kang reported that, despite a longer operative time, the robotic procedure leaves no scar on the neck surface with benefits for the patient on the aesthetic level. In our direct experience, the use of the robotic-assisted approach has been used for the first time during thyroid surgery operations, with an access from only one side and carrying out the complete removal up to the contralateral side.

Since 2005, Weinstein et al. ${ }^{3,4}$ described the use of transoral robotic surgery to take action against different pathologies that affect the neck area, and this procedure is widely used until today. ${ }^{5-11}$ However, it is possible to reach the same areas of interest through the transaxillary way, dividing the surgery into two separate events in case of bilateral interventions, but with a considerably reduced aesthetic impact on the patient. In our opinion, transaxillary robotic dissection must be performed with the preparation of robot access in the cleanest and most precise way possible, taking care of hemostasis to highlight the landmarks during dissection.

The retroauricular technique, developed by Lee et al. in 2012 and described in a study of 26 patients, ${ }^{12}$ uses a retroauricular incision similar to the one performed for parotidectomy operations, with, once more, the aim of reducing the aesthetic impact. Moreover, according to our experience, the retroauricular technique, avoiding the trauma of thoracic structures, prevents the formation of ecchymoses and hematomas, granting a faster recovery time [- Fig. 3]. The retroauricular approach in our experience is also useful in the exeresis of the submandibular and parotid glands, recently performed by our team and currently under study.

As demonstrated by our direct experience and by literature data, retroauricular approaches significantly reduce the aesthetic impact if compared with the conventional lateralcervical approach, making scars invisible. In 2013, Tae et al. showed in their study the use of a retroauricular approach with the support of a robotic device compared with conventional neck dissection, showing the overlap of the two techniques in terms of results obtained (on an oncological, functional and aesthetic level). ${ }^{13}$ In 2014, Greer Albergotti

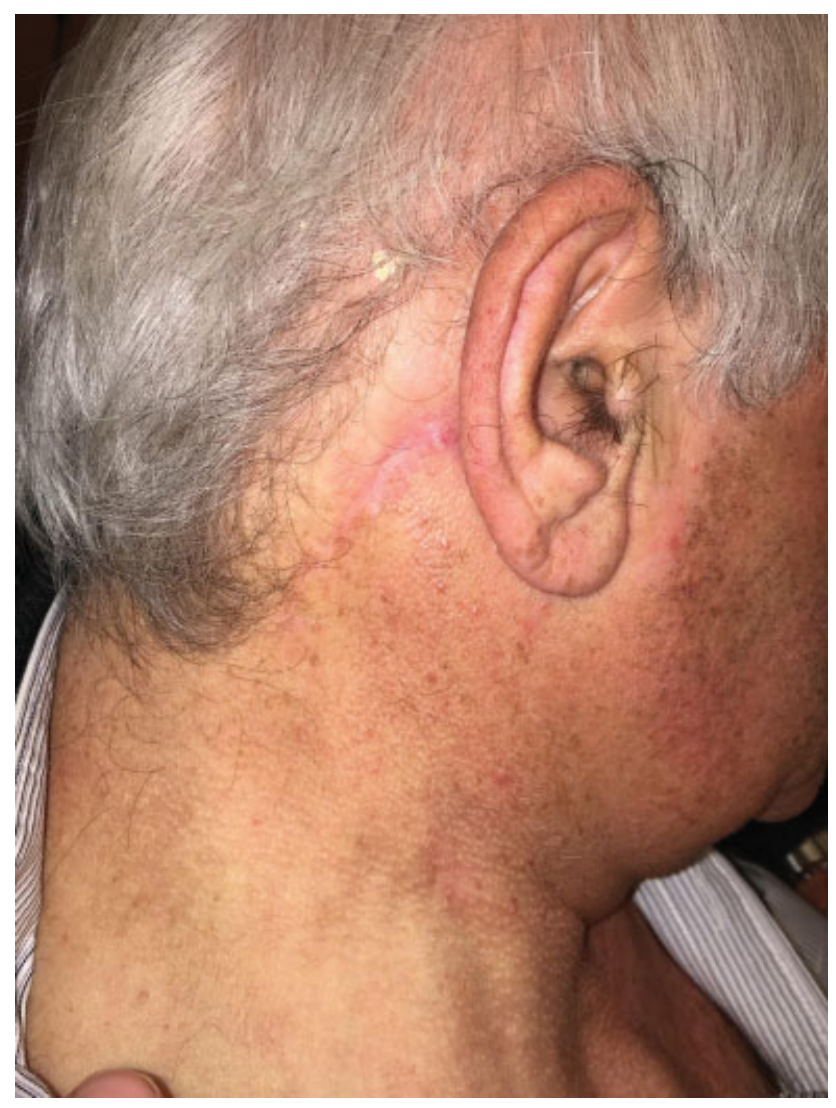

Fig. 3 Aesthetic result after 1 month of follow-up 
et al. described their initial experience with level II-IV neck dissection with a retroauricular approach, comparing the standard technique with a robotic-assisted one. ${ }^{14}$ Byeon et al. describe the procedure of neck dissection with a single retroauricular robotic approach to perform a total thyroidectomy with lymph nodal emptying, demonstrating how this approach can further reduce the aesthetic impact in thyroid surgery, although it is necessary to increase expertise to reduce surgical times. ${ }^{15}$ Lira et al. described the oncological and aesthetic efficacy of the retroauricular approach in lymph node emptying for oral cavity cancer. ${ }^{16}$

From our direct experience, the execution time of both techniques is certainly superior than the conventional technique, with the length of operations proportional to the number of procedures performed by the operator during the training phase. Therefore, we can affirm that the two robotic techniques, although similar in surgical times, are in an embryonic stage: not only they are not very widespread but, also, they are not the routine in all clinical centers. We can confirm that the retroauricular robotic techniques are the less invasive for the patient from a surgical point of view, as shown by the postoperative results and from the hospitalization time. The new single-port Da Vinci Xi technology will surely lead to a reduction in surgical time as lower intraoperative size and easy of positioning will facilitate the surgeon in small-space surgery such as the cervical-facial spaces. We also believe that the technological progress of robotic surgery with the use of the new single-port Da Vinci Xi robot, parallel to the spread of robotic surgery in common clinical practice, will lead to a reduction in surgical times in the future, making these procedures, to date exclusive of some centers, routine.

\section{Conclusion}

In our personal opinion, thanks to our direct experience, both robotic techniques represent a valid alternative for neck dissection to the open one; specific output results, from the point of view of aesthetic, oncological and functional efficiency, will be evaluated in the future when our case history can count on a greater number of operations performed. Focusing the attention only on the operation lengths, the fastest technique is still the classic one (with an open approach), because it is the most commonly used, the more standardized and the one with which operators have greater affinity.

\section{Conflict of interests}

The authors have no conflict of interests to declare.

\section{References}

1 Kang SW, Lee SH, Ryu HR, et al. Initial experience with robotassisted modified radical neck dissection for the management of thyroid carcinoma with lateral neck node metastasis. Surgery 2010;148(06):1214-1221

2 Kang SW, Lee SH, ParkJH, et al. A comparative study of the surgical outcomes of robotic and conventional open modified radical neck dissection for papillary thyroid carcinoma with lateral neck node metastasis. Surg Endosc 2012;26(11):3251-3257

3 Weinstein GS, O'Malley BW Jr, Hockstein NG. Transoral robotic surgery: supraglottic laryngectomy in a canine model. Laryngoscope 2005;115(07):1315-1319

4 Weinstein GS, O’Malley BW Jr, Snyder W, Hockstein NG. Transoral robotic surgery: supraglottic partial laryngectomy. Ann Otol Rhinol Laryngol 2007;116(01):19-23

5 Ciabatti PG, Burali G, D’Ascanio L. Transoral robotic surgery for large mixed laryngocoele. J Laryngol Otol 2013;127(04):435-437

6 Blanco RG, Ha PK, Califano JA, Saunders JM. Transoral robotic surgery of the vocal cord. J Laparoendosc Adv Surg Tech A 2011;21 (02):157-159

7 Park YM, Lee WJ, Lee JG, et al. Transoral robotic surgery (TORS) in laryngeal and hypopharyngeal cancer. J Laparoendosc Adv Surg Tech A 2009;19(03):361-368

8 Kayhan FT, Kaya KH, Sayin I. Transoral robotic cordectomy for early glottic carcinoma. Ann Otol Rhinol Laryngol 2012;121(08):497-502

9 Lawson G, Mendelsohn AH, Van Der Vorst S, Bachy V, Remacle M. Transoral robotic surgery total laryngectomy. Laryngoscope 2013;123(01):193-196

10 Dowthwaite S, Nichols AC, Yoo J, et al. Transoral robotic total laryngectomy: report of 3 cases. Head Neck 2013;35(11):E338-E342

11 Krishnan G, Krishnan S. Transoral robotic surgery total laryngectomy: evaluation of functional and survival outcomes in a retrospective case series at a single institution. ORL J Otorhinolaryngol Relat Spec 2017;79(04):191-201

12 Lee HS, Kim WS, Hong HJ, et al. Robot-assisted Supraomohyoid neck dissection via a modified face-lift or retroauricular approach in early-stage cNO squamous cell carcinoma of the oral cavity: a comparative study with conventional technique. Ann Surg Oncol 2012;19(12):3871-3878. Doi: 10.1245/s10434-012-2423-2

13 Tae K, Ji YB, Song CM, Jeong JH, Cho SH, Lee SH. Robotic selective neck dissection by a postauricular facelift approach: comparison with conventional neck dissection. Otolaryngol Head Neck Surg 2014;150(03):394-400. Doi: 10.1177/0194599813515431

14 Greer Albergotti W, Kenneth Byrd J, De Almeida JR, Kim S, Duvvuri U. Robot-assisted level II-IV neck dissection through a modified facelift incision: initial North American experience. Int J Med Robot 2014;10(04):391-396. Doi: 10.1002/rcs.1585

15 Byeon HK, Holsinger FC, Tufano RP, et al. Robotic total thyroidectomy with modified radical neck dissection via unilateral retroauricular approach. Ann Surg Oncol 2014;21(12):3872-3875. Doi: 10.1245/s10434-014-3896-y

16 Lira RB, Chulam TC, de Carvalho GB, et al. Retroauricular endoscopic and robotic versus conventional neck dissection for oral cancer. J Robot Surg 2018;12(01):117-129. Doi: 10.1007/s11701-017-0706-0 